\title{
Adolescent health: Priorities and opportunities for Rashtriya Kishor Swasthya Karyakram (RKSK) in Uttar Pradesh
}

Sapna Desai

Population Council

Follow this and additional works at: https://knowledgecommons.popcouncil.org/departments_sbsr-pgy

Part of the Demography, Population, and Ecology Commons, Family, Life Course, and Society Commons, Health Policy Commons, International Public Health Commons, and the Maternal and Child Health Commons How does access to this work benefit you? Let us know!

\section{Recommended Citation}

Desai, Sapna. 2017. "Adolescent health: Priorities and opportunities for Rashtriya Kishor Swasthya Karyakram (RKSK) in Uttar Pradesh," Policy brief. New Delhi: Population Council. 


\section{Adolescent health \\ Priorities and opportunities for Rashtriya Kishor Swasthya Karyakram (RKSK) in Uttar Pradesh}

\section{Introduction}

The Government of India in 2014 signaled its commitment to adolescent health through introduction of a national strategy, Rashtriya Kishor Swasthya Karyakram (RKSK). Targeting adolescents in ages 10-14 and 15-19, the programme aims to ensure universal coverage of health information and services for all adolescents - those in and out of school, married or unmarried, and vulnerable groups. Envisaged as a paradigm shift to address adolescent health beyond sexual and reproductive health, RKSK spans six domains: nutrition, sexual and reproductive health, mental health, injuries and violence including gender-based violence, substance misuse and non-communicable diseases (NCDs). This policy brief presents evidence on adolescent health from 2015-16 on the six RKSK priority areas, providing a baseline profile for the programme in Uttar Pradesh.

\section{Key Findings}

RKSK's strategy is aligned with the health burden found by the UDAYA study. Key issues are:

- Low levels of knowledge regarding sexual and reproductive health across all adolescents

- Distinct sexual and reproductive health risks that vary by marital status, age, and sex

- High prevalence of anaemia, especially amongst older and younger girls

- Mental health issues and intimate partner violence amongst married girls

- Tobacco use and injuries amongst older boys

\section{Services are weak. Challenges include:}

- Low engagement with frontline workers and very limited utilisation of Adolescent Friendly Health Clinics

- Ensuring peer educators can facilitate information exchange and increased use of services

- Developing a sustainable recruitment and training plan for peer educators

\section{Key opportunities for RKSK:}

- $\quad$ Improve awareness, strengthen or revamp service delivery, and evaluate outreach strategies

\section{The UDAYA study}

Understanding the lives of adolescents and young adults (UDAYA), a programme of research conducted by the Population Council, seeks to explore the situation and needs of younger (10-14 years) and older (15-19 years) adolescents, describe changes in their situation and needs over time, and assess factors that determine how they transition from adolescence to young adulthood. In Uttar Pradesh, the study includes two rounds of quantitative data collection, a policy and programme landscaping and qualitative sub-studies. In 201516, the Population Council collected quantitative data from a sample of unmarried girls and boys (10-14 and 15-19 years) and married girls aged 15-19. In 2018-19, we will re-interview this group, when they will be in ages 13-17 and 18-22, and collect data from a fresh sample of unmarried boys and girls (10-14 and 15-19 years) and married girls (15-19 years). This brief presents findings from the landscapingexerciseand descriptive and multivariate analyses of the 201516 survey of a representative sample of 10,161 adolescents. Anthropometric measurements and haemoglobin testing were also conducted among a sub-sample of participants in 2015-16. 


\section{RKSK Strategy}

The RKSK strategy expands a previous focus on curative care for adolescents to health promotion and prevention activities, primarily through established platforms such as frontline workers (FLWs) and youth clubs. New initiatives at the community level supported by RKSK include an Adolescent Health Day and a helpline. The strategy also calls for states to recruit dedicated counsellors at adolescent friendly health clinics (AFHCs) and at least four peer educators per village to establish groups, conduct participatory sessions, and facilitate referrals to AFHCs. Lastly, RKSK promotes coordination of activities for adolescents, both within Health and Family Welfare and across relevant departments such as Women and Child Development and Youth Affairs and Sports.

\section{Persistent Burdens: Anaemia and poor sexual and reproductive health}

\section{Nutrition}

Malnutrition and anaemia were common amongst adolescents (Table 1). Three in 10 boys in ages 1014 years were classified as thin. While thinness was less prevalent amongst girls, between 21-30 percent of unmarried and married girls displayed moderate or severe anaemia. Overall, close to 2 in 3 girls and 1 in 3 boys presented with any anaemia. Less than five percent of adolescents were overweight or obese, with a slightly higher prevalence in urban areas.

Table 1: Nutritional status amongst adolescents

\begin{tabular}{|lccccc|}
$\begin{array}{l}\text { Nutritional } \\
\text { indicator }\end{array}$ & $\begin{array}{c}\text { Boys } \\
(10-14)\end{array}$ & $\begin{array}{c}\text { Boys } \\
(15-19)\end{array}$ & $\begin{array}{c}\text { Girls } \\
(10-14)\end{array}$ & $\begin{array}{c}\text { Unmarried } \\
\text { girls } \\
(15-19)\end{array}$ & $\begin{array}{c}\text { Married } \\
\text { girls } \\
(15-19)\end{array}$ \\
\hline Thinness & 29.6 & 19.6 & 19.8 & 10.7 & 10.8 \\
\hline Mild anemia & 28.8 & 19.3 & 39.8 & 44.0 & 36.8 \\
\hline $\begin{array}{l}\text { Moderate/ } \\
\text { severe anemia }\end{array}$ & 8.4 & 13.2 & 14.0 & 20.7 & 29.5 \\
\hline
\end{tabular}

\section{Sexual and Reproductive health}

\section{Menstrual hygiene}

RKSK's menstrual hygiene scheme aims to promote use of sanitary napkins. About 30 percent of girls in ages 10-14 were not aware of menstruation, with little difference between respondents from urban and rural areas. Amongst menstruating girls, about 1 in 2 rural girls used either only napkins or a combination of napkins and cloth, with higher use of sanitary napkins in urban areas (Figure 1). Few girls received sanitary napkins from their schools or FLWs (3-4\% of unmarried and married older girls). Affordability was the leading reason reported for non-use of sanitary napkins, followed by concerns related to access or shyness for rural girls awareness.
Figure 1: Use of sanitary napkins amongst adolescent girls in rural and urban areas

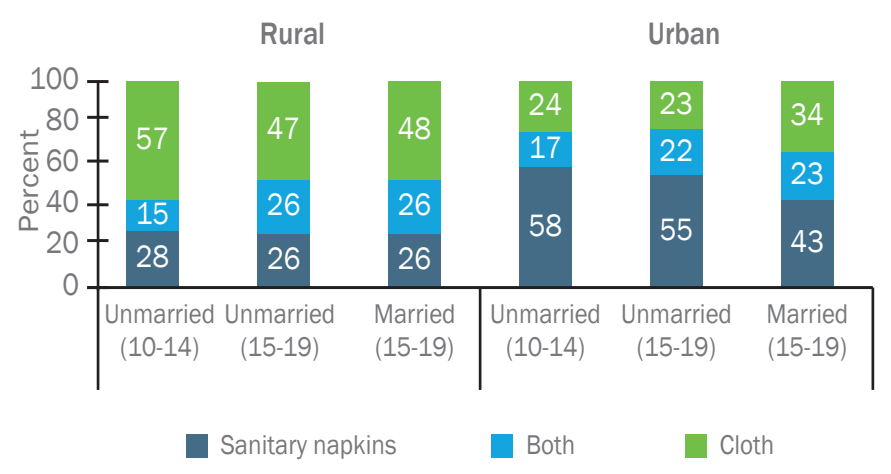

\section{Genital infections and menstrual problems}

Amongst older adolescents, 22-38 percent reported experiencing symptoms of genital infections (such as genital ulcers, itching, swelling, abnormal discharge) in the previous three months. Treatment-seeking varied across groups: about 1 in 2 married girls, 2 in 3 unmarried boys, and 1 in 4 unmarried girls reported seeking care (Figure 2). Boys sought treatment primarily from medical shops and private sector providers, while the majority of girls utilised private sector providers. Other sources of treatment were home remedies and unqualified practitioners, along with government providers (utilised by 19-26 percent of adolescents). Menstrual problems affected 11 percent of older unmarried and married girls, of whom 31-37 percent reported seeking treatment, mostly in the private sector.

Figure 2: Prevalence of self-reported symptoms of genital infection and treatment-seeking, 15-19 years

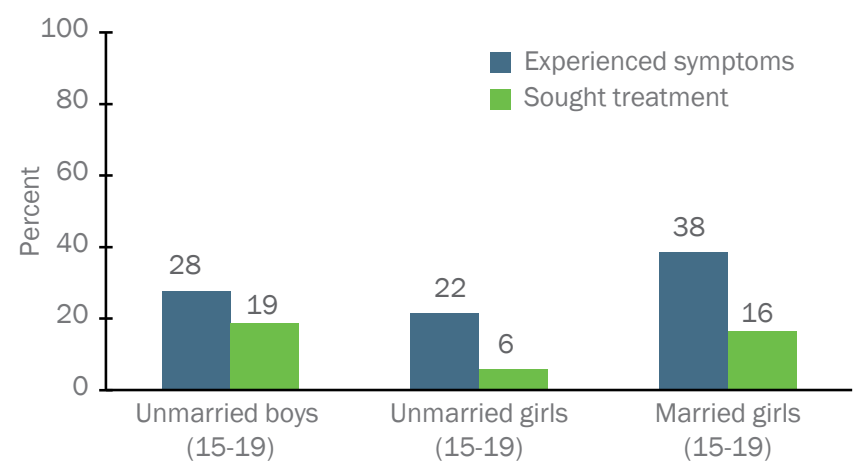

Sexuality and sexual health

Seventeen percent of boys and 6-10 percent of unmarried and married girls reported having had premarital sex. Amongst older adolescents, a little less than a quarter of unmarried girls and boys, and 1 in 2 married girls, knew that a woman can get pregnant at first sex. Less than 1 in 5 older boys and 6-7 percent of older girls demonstrated comprehensive knowledge of HIV/AIDS. 


\section{Contraception}

Correct, specific knowledge of condoms was reported by almost 3 in 4 older adolescent boys and 3 in 5 married girls - and only 1 in 8 unmarried girls in ages 15-19. Correct knowledge of oral contraceptives and emergency contraception was considerably low across all groups (Figure 3).

Figure 3: Correct, specific knowledge of contraception, 15-19 years

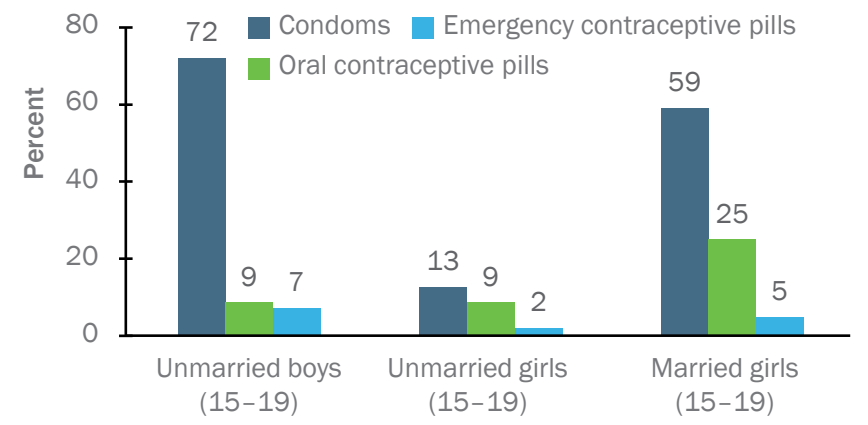

About 1 in 2 married girls reported wanting to space or limit childbearing. Thirteen percent of married girls who had begun cohabiting reported using contraception to delay the first birth, and 12 percent reported currently using contraception (mostly condoms).

Figure 4: Contraceptive use and unmet need amongst married girls, 15-19 years

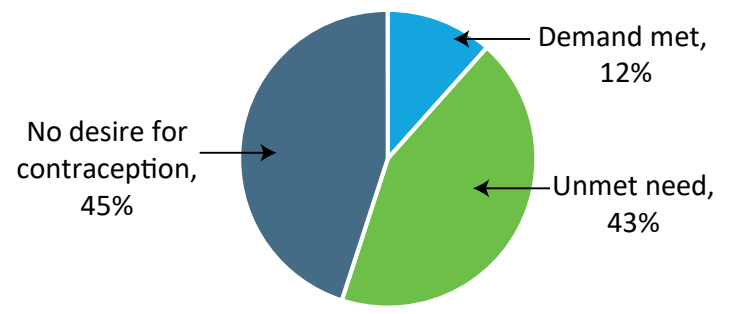

The remainder either had unmet needs (43\%) or did not desire to delay pregnancy at present (Figure 4). About 2 in 3 of all married girls reported they would feel shy approaching either a healthcare provider or medical shop for contraceptives.

\section{Maternal health services}

Amongst all married girls, approximately 1 in 3 were aware that a pregnant woman should have at least four antenatal checkups. Forty-one percent of cohabiting, married girls had begun childbearing. However, most girls had not received the full continuum of maternal and child health services (Figure 5).
Figure 5: The continuum of maternal and child health care (first birth)

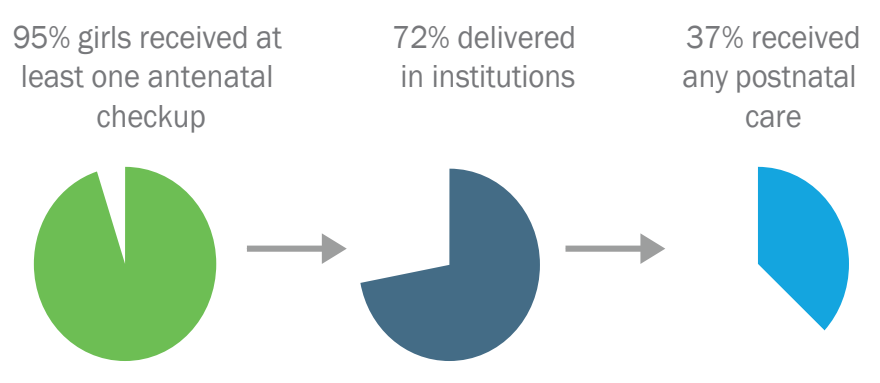

\section{Gender-based violence}

Four in ten (43\%) of married girls cohabiting with their partners reported ever experiencing either emotional, physical or sexual violence within their marriage (Figure 6).

\section{Figure 6: Violence ever experienced in marriage by married girls, $15-19$ years}

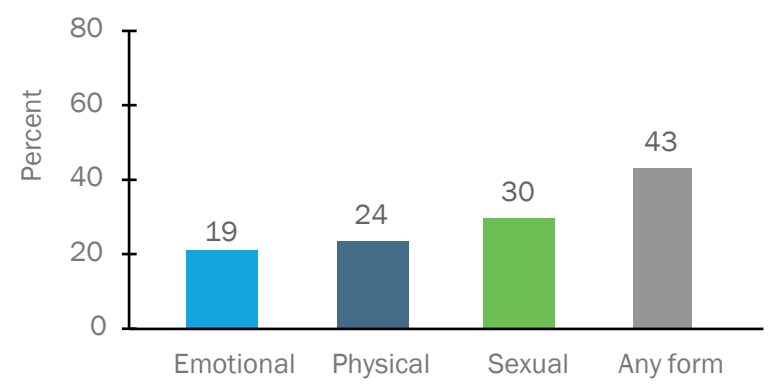

Thirty-six percent of girls reported experiencing either physical or sexual violence in the last year. A considerable proportion of both boys and girls adhered to attitudes that normalise violence-in marriage, amongst peers and in the community (Table 2). Same-sex physical fights appeared to be common amongst boys and younger girls.

\section{New burdens: prevalence and risk factors related to non-communicable diseases}

UDAYA's estimates of mental health issues, injuries, and substance use confirm the need for adolescent-specific strategies. Overall, older adolescent girls reported the highest prevalence of symptoms of depression (Figure 7). Amongst married girls, nine percent reported both symptoms of moderate to severe depression in the previous two weeks, and nine percent also reported suicidal ideation.

Table 2: Involvement in and attitudes towards physical violence

\begin{tabular}{lcccc} 
& $\begin{array}{c}\text { Boys } \\
(10-14)\end{array}$ & $\begin{array}{c}\text { Unmarried boys } \\
(15-19)\end{array}$ & $\begin{array}{c}\text { Girls } \\
(10-14)\end{array}$ & $\begin{array}{c}\text { Unmarried girls } \\
(15-19)\end{array}$ \\
$\begin{array}{l}\text { Justified wife-beating if wife does not listen to or obey } \\
\text { husband }\end{array}$ & - & 29.5 & -19.9 & 27.4 \\
$\begin{array}{l}\text { Involved in physical fights with individuals of same-sex } \\
(15)\end{array}$ & 44.9 & 26.6 & 29.5 & 9.8 \\
$\begin{array}{l}\text { Believe it is acceptable to beat up someone who } \\
\text { insults a female family member }\end{array}$ & 59.1 & 65.6 & 46.0 & 41.0 \\
\hline
\end{tabular}




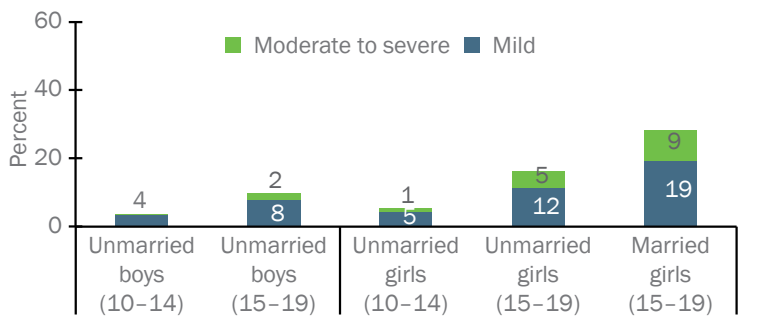

Injuries in the previous three months - highest among boys - were caused mostly by fights, falls or animal bites, with 8-9 percent of younger and older boys reporting injuries from road accidents. About 1 in 6 older boys reported using tobacco at least once per week, suggesting early exposure to risk factors for cardiovascular and lung disease. Reported alcohol use was minimal.

UDAYA also estimated physical inactivity, a leading risk factor for NCDs. Both younger and older boys, as well as younger girls, reported high levels of regular engagement in sports and games - compared to less than half of unmarried girls and 1 in 8 married girls.

\section{Wide opportunities exist for service outreach and tracking}

UDAYA indicated that most adolescents had heard of anganwadi workers (AWW) and Accredited Social Health Activists (ASHAs) - suggesting that these FLWs are well-placed to reach adolescents with information and services. However, just 31 percent of married girls reported interactions with FLWs, primarily for information related to reproductive health. Deworming and iron and folic acid outreach were poor across all groups. Amongst students currently enrolled in school, 20 percent or less reported receiving information from the School Health Programme or similar initiatives. Exposure to family life education was similarly low. Virtually no respondents had utilised AFHCs in the previous year.

\section{Policy and programme insights}

With both national guidelines and increasing political priority, RKSK is positioned to address the specific needs of adolescents. Many aspects require coordination between a range of existing service providers at the community level, and integration with ongoing initiatives such as the Integrated Child Development Services.

In Uttar Pradesh, implementation of RKSK's key services - AFHCs, peer education, menstrual hygiene and iron folic acid supplementation was initiated in 25 high priority districts, with subsequent roll-out in other districts. For example, infrastructure for adolescent friendly services was available in 57 of 75 districts and iron folic acid supplementation had reached 40 districts at the time of the study. UDAYA was conducted in the initial stages of the programme. Accordingly, as data indicate, implementation and outreach of many services have been limited thus far. While RKSK tracks monitoring data, analysis of indicatorbased, disaggregated information will be required to assess both outreach and quality of specific services.

Discussions with policymakers and programme implementers indicated that the roll-out of RKSK has intensified in the past year. However, procurement issues, recruitment, training and coordination between multiple departments had led to a delay in some services. Although service providers such as FLWs are available in the community, they require greater integration into the RKSK system and orientation on how to reach adolescents. Similarly, counselors for AFHCs reported the need for training on both technical knowledge and communication skills, which is being planned through RKSK. In the case of menstrual hygiene, reaching out-of-school adolescents warrants specific strategies. Difficulty in recruiting and retaining peer educators and counselors remains a challenge.

As part of RKSK, Uttar Pradesh implemented its first Adolescent Health Day in October 2016. Policymakers noted the potential for these days to promote greater intersectoral convergence to reach adolescents with a variety of programmes available in the states, such as for skill building. Improved, more cohesive, health communication and communication strategies emerged as a need across services. Lastly, evaluation emerged as a key need for newly implemented services for adolescents. For example, assessing the use, approachability and utility of adolescent friendly health services was cited as one area for further study.

Figure 8: Services received by adolescents, 2015-16

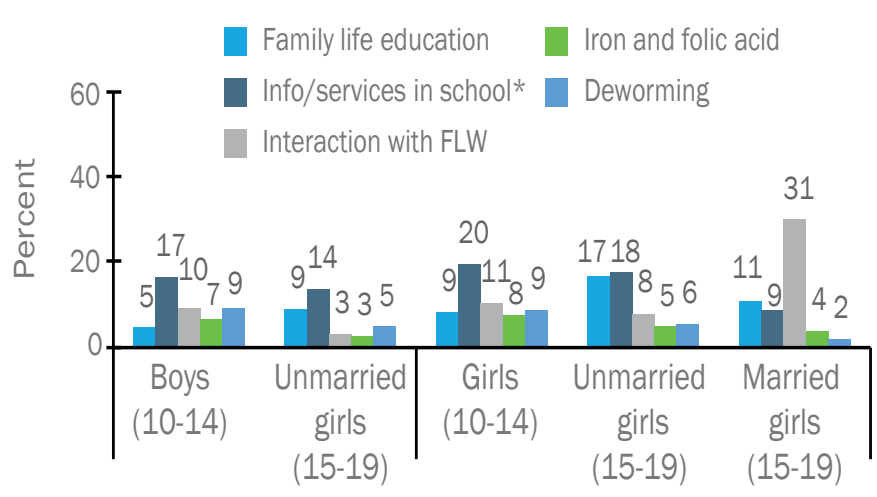

Note: *Information and services limited to those currently enrolled in school 


\section{Recommendations}

\section{Priority areas}

\section{Anemia and healthy dietary practices}

Anaemia was widespread, particularly amongst girls. Given low reach of supplementation, improved distribution of iron and folic acid must be a priority, along with implementation research to inform a potential re-framing of the scheme. Understandable, context-specific information on nutrition and dietary practices should be a priority within health education programmes.

\section{Improve SRH knowledge and behaviour}

Gaps in knowledge about safe sex practices and contraception must be addressed urgently. Expansion of the Adolescent Education Programme, and strengthening of age-appropriate family life or comprehensive sexuality education for all adolescents, is required. Evidence from NGO-led programmes that combine sexuality and life-skills education have shown promise in raising awareness of sexual and reproductive matters and helping to adopt protective behaviours. ${ }^{1,2}$ ASHAs must also improve provision of contraception to married girls to address the high unmet need documented in this group.

\section{Violence prevention and interventions}

The prevalence of intimate partner violence calls for strategies both to prevent violence and provide support services. Pilot interventions in India, such as Do Kadam Barabari ki Ore in Bihar, that hold promise are: gender transformative life skills education, sports coaching to change attitudes towards violence, and training FLWs to identify and provide services for women at risk of violence. ${ }^{3,4,5}$

\section{Mental health}

The prevalence of depression indicates the need for scalable strategies, especially for married girls. Emerging evidence in India suggests that community-based mental health interventions such as life skills education, counselling, and employing lay persons to screen/identify at-risk persons may help address symptoms of mental disorders. $6,7,8,9$

\section{Strengthen information dissemination}

RKSK is investing in peer educators, FLWs and community events to bring information to adolescents. Peer educators and FLWs must be equipped with adolescent-specific communication materials, and must be trained in how to break down barriers to reach adolescents effectively.
UDAYA found that over 90 percent of older adolescent boys and 84-93 percent of older girls had access to a mobile phone, and approximately 2 in 3 older adolescent boys and 1 in 2 older girls reported regular exposure to television and films. Accordingly, while community-based efforts should continue to focus on the most vulnerable, media and technology may help to expand and reinforce messaging.

\section{Ensure strong monitoring, evaluation and implementation research}

\section{Outreach activities of frontline workers}

FLWs reached just around 1 in 10 or less unmarried adolescent girls and boys, and community-based services such as deworming and sanitary napkins had minimal reach. Feasibility and effectiveness of existing FLWs in reaching adolescents should be examined to identify delivery improvement strategies and barriers to outreach.

\section{Peer educators}

As RKSK envisions peer educators as information sources as well as referral links to AFHCs, it will be critical to monitor their role in practice and examine whether and how they can best be deployed to improve knowledge and use of health services. Tracking of the implementation and costs associated with ongoing recruitment, training and attrition as adolescent peers age out of their roles is recommended-along with evaluation of the effectiveness of the programme.

\section{Adolescent Friendly Health Clinics}

AFHCs were virtually unused by adolescents, and a small proportion of adolescents reported use of any government services for symptoms of genital infections. RKSK must evaluate the continued use of AFHCs and whether use of outreach efforts is effective in increasing utilisation. Additional strategies such as expanding the provider base in the public and private sector and generating demand through social marketing should also be explored and evaluated.

\section{Acknowledgements}

The author is grateful to Nicole Haberland and K.G. Santhya for insightful comments on earlier versions of this brief, to Tripti Pant Joshi for the landscaping exercise, and to the Bill \& Melinda Gates Foundation and the David \& Lucile Packard Foundation for financial support for UDAYA.

This brief is based on data collected by the UDAYA study, the report of which is available at www.projectudaya.in ${ }^{10}$ 
Ideas. Evidence. Impact.

\section{References}

1. Pandey, N., S. J. Jejeebhoy, R. Acharya et al. 2016. Effects of the PRACHAR Project's Reproductive Health Training Programme for Adolescents: Findings from a Longitudinal Study. New Delhi: Population Council.

2. Mehra,S., R.R.Singh,V.Nair, etal.2016.Addressingadolescentgirls' vulnerability to HIV/AIDS: Lessons from the Meri Life Meri Choice project. New Delhi: Population Council.

3. Jejeebhoy, S.J., R. Acharya, N. Pandey et al. 2017a. The Effect of a Gender Transformative Life Skills Education and Sports-Coaching Programme on the Attitudes and Practices of Adolescent Boys and Young Men in Bihar. New Delhi: Population Council.

4. Jejeebhoy, S. J., K. G. Santhya, S. Singh et al. 2017b. Feasibility of Screening and Referring Women Experiencing Marital Violence by Engaging Frontline Workers: Evidence from Rural Bihar. New Delhi: Population Council.

5. Das, A, E. Mogford, S. Singh et al. 2012. "Reviewing responsibilities and renewing relationships: an intervention with men on violence against women in India," Culture, Health and Sexuality 14(6): 559-675.

6. Srikala, B and Kishore Kumar K. V. 2010. "Empowering adolescents with life skills education in schools - School mental health program: Does it work?," Indian Journal of Psychiatry 52(4): 344-49.

7. Balaji, M., T. Andrews, G. Andrew, et al. 2011. "The acceptability, feasibility, and effectiveness of a population based intervention to promote youth health: An exploratory study in Goa, India," Journal of Adolescent Health 48(5): 453-60.

8. Rajaraman, D., S. Travasso, A. Chatterjee, etal. 2012. "Acceptability, feasibility and impact of a lay health counselor delivered health promoting schools programme in India: a case study evaluation," BMC Health Services Research 12:127.

9. Patel, V., H. A. Weiss, N. Chowdhary et al. 2010. "Effectiveness of an intervention led by lay health counsellors for depressive and anxiety disorders in primary care in Goa, India (MANAS): A cluster randomised controlled trial," The Lancet 376(9758): 2086-95.

10. Santhya, K.G., R. Acharya, N. Pandey, et al. 2017. Understanding Lives of Adolescents and Young Adults (UDAYA) in Uttar Pradesh. New Delhi: Population Council.

Study supported by

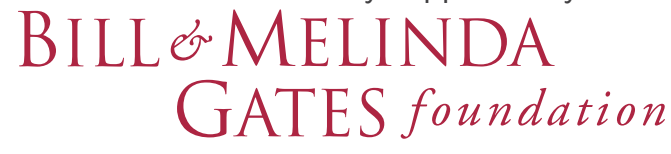

the David

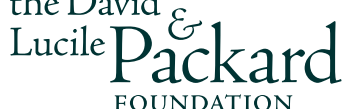

The Population Council confronts critical health and development issues-from stopping the spread of HIV to improving reproductive health and ensuring that young people lead full and productive lives. Through biomedical, social science, and public health research in 50 countries, we work with our partners to deliver solutions that lead to more effective policies,programs, and technologies that improve lives around the world. Established in 1952 and headquartered in New York, the Council is a nongovernmental, nonprofit organization governed by an international board of trustees.

\section{Suggested Citation}

Desai, S. 2017. Adolescent health: Priorities and opportunities for Rashtriya Kishor Swasthya Karyakram (RKSK) in Uttar Pradesh. Policy Brief. New Delhi: Population Council. 